Original Article (short paper)

\title{
Project PANK: Rationale, study protocol and baseline results of a multidisciplinary school based intervention in children with cardiovascular and metabolic risk factors.
}

\author{
Rui Batalau \\ Universidade Lusófana de Humanidades e Tecnologias, Campo Grande, Lisboa, Portu- \\ gal, CIDEF, Instituto Superior Manuel Teixeira Gomes, Portimão, Portugal \\ CIDEF (Centro de Investigação em Desporto e Educação Física) \\ Joana Cruz \\ CIDEF, Instituto Superior Manuel Teixeira Gomes, Portimão, Portugal \\ Ricardo Gonçalves \\ Magda Santos \\ João Leal \\ CIDEF, Instituto Superior Manuel Teixeira Gomes, Portimão, Portugal \\ António L. Palmeira \\ Universidade Lusófona de Humanidades e Tecnologias, Campo Grande, Lisboa, Portugal, CIPER, Fa- \\ culdade de Motricidade Humana, Universidade Técnica de Lisboa, Lisboa, Portugal \\ CIPER (Centro Interdisciplinar de Estudo da Performance Humana)
}

\begin{abstract}
Aims: Cardiovascular disease risk factors occur more frequently in children with obesity. Project PANK is a multidisciplinary school-based intervention lasting 6 months to improve BMI z-score, waist circumference (WC), waist-to-height ratio (WHtR), blood pressure (BP), nutrition, physical activity (PA), sedentary behaviour (SB), cardiorespiratory fitness (CRF), glucose, cholesterol, and triglycerides (TG). Methods/Design: A total of 77 children (7-10 years) were recruited from an urban school. The protocol includes PA and SB individual meetings for children/ parents; increasing school exercise; PA and SB lessons for children; A goal in the number of steps/day to accomplish in and after school. In nutrition, the protocol includes three individual meetings for children/parents and six lessons for children. Results: Positive associations were found between the BMI Z-score, WC, and WHtR with TG; the BMI Z-score and WHtR with glucose; the light PA time and HDL-C; the vigorous and moderate-to-vigorous PA with CRF; the caloric intake and lipids with LDL-C, BMI z-score, WC, and WHtR. A negative association was found between CRF and TG. Conclusion: Baseline results stress the importance of multidisciplinary school-based interventions. We hypothesized that PANK will improve blood variables, anthropometric measures, and BP, by changing food intake, enhancing PA and CRF, and decreasing SB.
\end{abstract}

Keywords: cardiovascular and metabolic risk factors, physical activity, nutrition, sedentary behaviour, children

\section{Introduction}

Recent findings indicate that cardiovascular disease risk factors occur more frequently in children with obesity ${ }^{1}$. Obesity prevalence among children and adolescents is on the rise ${ }^{2}$. If current trends continue the number of overweight or obese infants and young children globally will increase to 70 million by $2025^{3}$. Atherosclerosis begins in childhood and this process is related to the presence and level of known cardiovascular disease risk factors, such as, overweight/obesity, but also nutrition/diet, and insufficient physical activity (PA) ${ }^{4}$. Recently, a study found a significant prevalence of metabolic syndrome among obese Portuguese schoolchildren ${ }^{5}$. Given that the risk of an obese child becoming an obese adult increases from $25 \%$ before 6 years of age to $75 \%$ during adolescence, the treatment must be initiated as early as possible ${ }^{2}$. Overweight and obesity, as well as their related diseases, are largely preventable ${ }^{3}$. Obesity prevention programmes focusing on both decreasing sedentary time and increasing PA has been highlighted for European children ${ }^{6}$.

The PA and eating behaviour are considered modifiable behavioural risk factors influencing physical fitness and body weight that are related to the metabolic risk factors ${ }^{7}$. However, a recent meta-analysis of controlled trials with objectively measured outcomes showed that PA interventions have had only a small effect on children's overall activity levels ${ }^{8}$. The benefits of regular PA on health are well established ${ }^{9-11}$. Observational studies indicate that the more PA, the greater the health benefit and results from experimental studies indicate that even modest 
amounts of PA can have health benefits in high-risk youngsters ${ }^{12}$. There is evidence for the effectiveness of combined weight loss programs that included behaviour change counselling, negative energy balance through diet, and increased PA in addressing obesity in children older than age 6 years ${ }^{4}$. Ongoing nutrition counseling has been effective in assisting children and families to adopt and sustain recommended diets for both nutrient adequacy and reducing cardiovascular risk ${ }^{4}$, although its inclusion in multidisciplinary programmes remains scarce. In children, reduction in sedentary behaviour (SB), independent of increasing $\mathrm{PA}$, produced weight loss and were effectively accomplished by rewarding children for time spent being physically active with TV viewing time ${ }^{4}$. Frequent interruptions in sedentary time are associated with a favourable cardiometabolic risk profile and highlight the deleterious relationship between screen time and cardiometabolic risk among children with a family history of obesity ${ }^{13}$. Another review found associations between children's screentime and obesity, blood pressure (BP), total cholesterol (TC), self-esteem, physical fitness and academic achievement ${ }^{14}$.

A last review focused on diet and PA presented results about effective interventions in school settings, showing improvements in knowledge and attitudes, behaviour and, when tested, physical and clinical outcomes, suggesting that school should support the adoption of healthy diets and $\mathrm{PA}^{11}$. Schools are in an unique position to promote healthy dietary behaviours and help ensure appropriate food and nutrient intake'.

Therefore, the Project PANK(PhysicalActivity and Nutrition for Kids) follows high-intensity school-based interventions and was designed to be a comprehensive and multi-component approach through a significant curriculum in PA and nutrition taught by trained experts and a parental component ${ }^{11}$. The objective of this 6-month multidisciplinary intervention was to enhance PA and cardiorespiratory fitness (CRF), decrease SB, and change eating behaviour in order to improve glucose, TC, HDL-C, LDL-C, triglycerides (TG), BMI z-score, waist circumference (WC), waist-to-height ratio (WHtR), and BP among elementary urban Portuguese children. The secondary outcomes are PA, $\mathrm{SB}, \mathrm{CRF}$, and nutrition.

\section{Methods}

\section{Setting and Participants}

A total of 77 children (girls $40.3 \%$ and boys 59.7\%), aged 7 to 10 years, were recruited after a cross-sectional study carried out in a Portuguese primary public urban school. This cross-sectional study was implemented as a strategy to achieve adequate participant enrollment. Participants were randomly assigned by classroom in experimental (EG) or control group (CG) (Figure 1 provides an overview of the trial flow). The assignment to groups was determined before baseline testing. The method of generating the allocation sequence was the computer-generated random numbers. The coordinator generated the allocation sequence, enrolled participants, and assigned participants to intervention. School meals, books, and academic material eligibility were used to determine socioeconomic status (SES). The children's SES was also categorized in 3 groups (low - free books, academic material and nutrition, middle - partial financial support for books, academic material and nutrition, and high - without any financial support), taking into account the employment circumstances of the parents and their annual financial income. Prior to participation, all participants and their parents or guardians were provided with a detailed written description of the project. An opportunity was given to ask research staff questions and allowed to take their time to decide whether prior to sign the consent form.

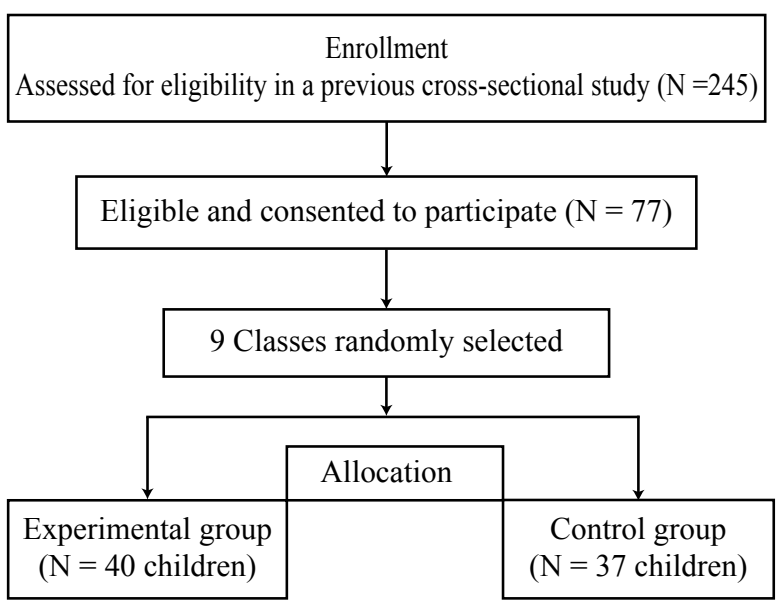

Fig.1. Trial Flow

\section{Inclusion and Exclusion Criteria}

The participants eligible for the trial had to comply with all of the following at randomization: $a$. Age $\geq 7$ and $\leq 10$ years; $b$. The presence of, at least, one variable associated with cardiovascular and metabolic risk factors development. The overweight and obesity condition were the most used inclusion criteria; c. Participants and legal guardians who signed the informed consent forms. The exclusion criteria were: a. Participants who take medications that affect the study variables; $b$. Participants with disabilities or severe motor handicaps; c. Participants with relevant health problems (for example, children suffering from chronic disease that prohibited the PA program); d. Participants who manifest incapacity to perform all the steps of the study.

\section{Intervention}

Given the complexity of factors associated with both overweight and obese children status, a multidisciplinary intervention was designed involving PA and nutrition (Figure 2 provides the content and intervention timeline). This was a comprehensive and multi-component approach through a significant curriculum in PA and nutrition through individual meetings, educational lessons, more physical exercise at school and a PA goal-setting task associated with the number of steps/day.

The intervention was designed to use methods developmentally appropriated because educational strategies should match the different stages of students' cognitive development ${ }^{1}$. For 
example, interventions focused on concrete experiences, such as increasing exposure to many healthy options and building skills in choosing the healthier, solving several individual and group tasks, and guided discovery tasks ${ }^{15-17}$. Additionally, interactive strategies were used for the individual meetings and educational sessions because students are more likely to adopt healthy eating PA behaviours when they learn about these behaviours through enjoyable, participatory activities rather than through lectures ${ }^{15,16}$. Lessons emphasized the positive, appealing aspects of PA and healthy eating patterns rather than the adverse consequences and present the benefits in the setting of what is already important to students ${ }^{18,19}$. Students had several opportunities to practice PA and healthy eating behaviours that are relevant to their daily lives ${ }^{20,22}$.

\begin{tabular}{|c|c|c|c|c|c|c|}
\hline \multicolumn{7}{|c|}{ Baseline Assessement/ 1st Assessement } \\
\hline $\begin{array}{c}\text { Blood } \\
\text { samples }\end{array}$ & $\begin{array}{c}\text { Blood } \\
\text { pressure }\end{array}$ & $\begin{array}{c}\text { Anthropometric } \\
\text { measures }\end{array}$ & Nutrition & $\begin{array}{c}\text { Cardiorespiratory } \\
\text { fitness }\end{array}$ & $\begin{array}{c}\text { Physical } \\
\text { activity }\end{array}$ & $\begin{array}{c}\text { Sedentary } \\
\text { behaviour }\end{array}$ \\
\hline
\end{tabular}

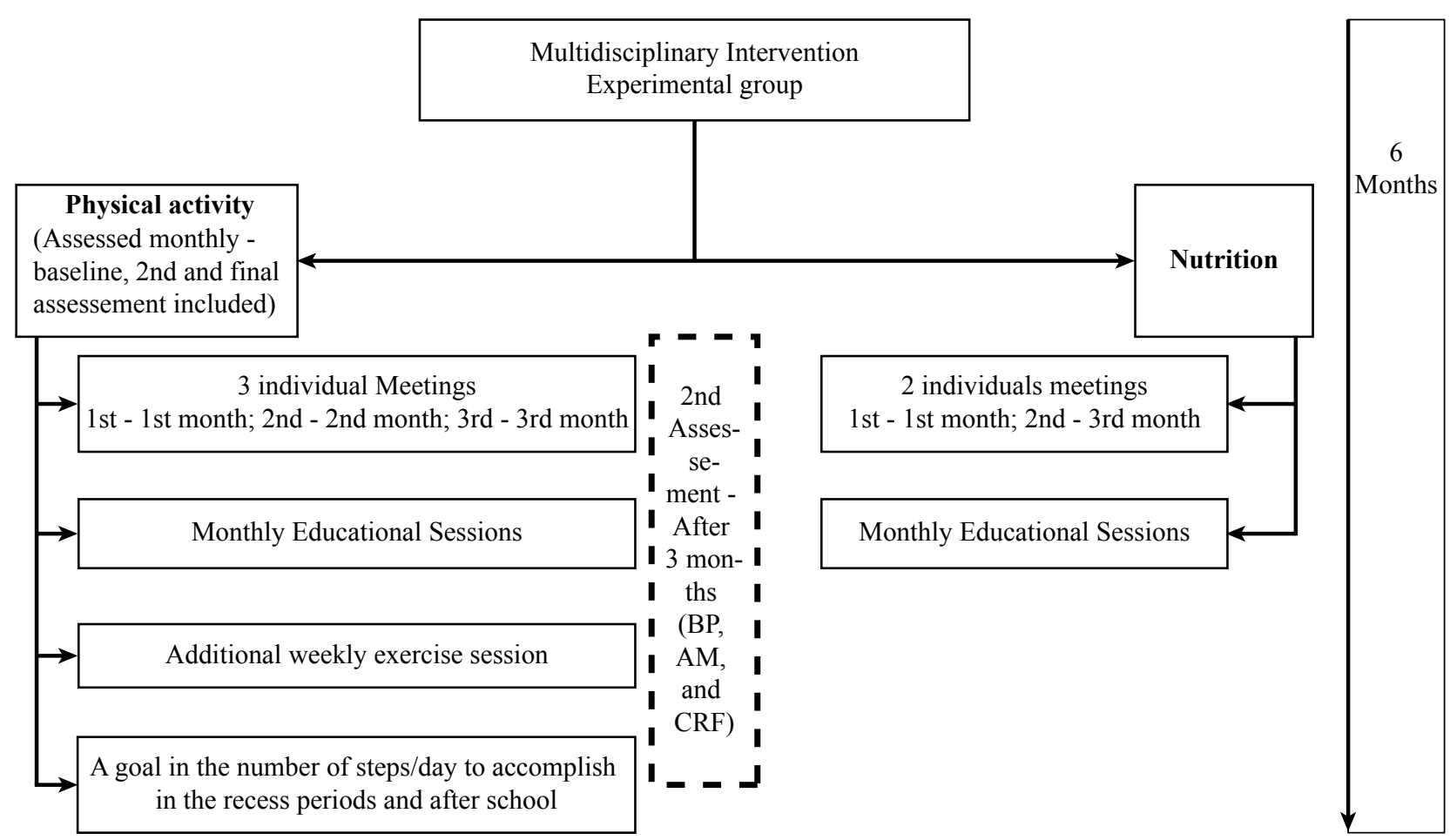

\begin{tabular}{|c|c|c|c|c|c|c|}
\hline \multicolumn{7}{|c|}{ Final Assessement/ 3rd Assessement - After 6 months } \\
\hline $\begin{array}{c}\text { Blood } \\
\text { samples }\end{array}$ & $\begin{array}{c}\text { Blood } \\
\text { pressure }\end{array}$ & $\begin{array}{c}\text { Anthropometric } \\
\text { measures }\end{array}$ & Nutrition & $\begin{array}{c}\text { Cardiorespiratory } \\
\text { fitness }\end{array}$ & $\begin{array}{c}\text { Physical } \\
\text { activity }\end{array}$ & $\begin{array}{c}\text { Sedentary } \\
\text { behaviour }\end{array}$ \\
\hline
\end{tabular}

Fig. 2. Content and timeline of intervention

\section{Physical Activity Intervention}

The overall project in the component related to PA and SB was comprised of four components including: C1) Three PA and SB individual meetings with a trained expert for children and parents or legal guardians; C2) Increasing school exercise providing an additional exercise session, in addition to the two physical education lessons per week included in school program; C3) Six PA and SB educational lessons for children to improve the knowledge and behaviours regarding PA and SB; C4) The fourth component was a PA goal-setting task associated with the number of steps/day to accomplish in the recess periods and after school. A pedometer and a diary were used for this component, during three weeks ${ }^{23,24}$.

In the three PA and SB individual meetings with a trained expert to the children and parents or legal guardians, the aim of the first meeting at baseline was to apply a PA questionnaire to assess curricular and extracurricular PA, as well as, school transportation and PA patterns on the recess periods. Additionally, an adapted version of the Adolescent Sedentary Activity Questionnaire (ASAQ) to the children's parents in respect of SB of the child was applied. The aim of the answers 
interpretation period was to give advices about how children can increase daily PA in and out of the school setting and to define strategies to decrease daily SB. The behaviour change related to increase the amount of PA and to reduce SB was done through the PA pyramid.

In the second meeting (in the second month of the intervention), the goal was to show the summary results of the baseline assessment by accelerometer and the results of CRF test, comparing respectively with the international recommendations and the references according to age and sex. In this meeting, a summarized report about daily SB, light PA (LPA), moderate PA (MPA), vigorous PA(VPA), and the steps, considering week and weekend days were analysed and new strategies and commitments were defined to increase PA and decrease SB in order to improve CRF. In the third meeting (in the third month of the intervention), the main goal was to show again the summary report of the second PA and SB assessment by accelerometer, as well as $\mathrm{CRF}$, comparing with baseline results. Accordingly, the aim was to make a new commitment with the parents and the children to promote other PA and SBrelated behaviours changes.

Additionally, in the six educational practical sessions (one per month) in small groups during 30 minutes about healthy lifestyles, a trained expert did activities aimed to improve children's knowledge on how to increase daily PA and decrease SB. For each session, it was defined a specific subject matter and related tasks: Session 1: PA - Top 10 benefits (guided discovery); Session 2: PA Pyramid, types of exercise and recommendations - New homework's!; Session 3: SB and Small Screen Recreation; Session 4: PA and Lifestyle - How many daily PA and Steps? Strategies; Session 5: How to increase daily PA in school recess?; Session 6: Body weight and PA.

The third component of PA intervention was the increase of exercise in the classroom through an additional hour of exercise per week, further the two physical education lessons included in school program with a trained expert in physical education and in exercise in youth. The content of the additional hour of exercise per week was focused on essential fitness components: motor skills, aerobic fitness, strength training and impact loading. Lessons normally included 5 minutes of warming up and cooling down each, 30 minutes of MVPA through running tasks, and 20 minutes of strength training for upper body, core and lower body through movement patterns: reaching, pushing, pulling, lifting, squating, lunging, jumping, and gait. Importantly a positive and motivating setting, creating positive feelings and attitudes towards PA, was pursued.

In all components, the parental engagement was very important because trained experts repeatedly emphasized the parental role as models in the process ${ }^{2}$.

\section{Nutrition Intervention}

At the same time, EG had a nutrition intervention by a nutrition expert. In nutrition intervention the main goal was to promote energy balance through the change of eating behaviour, improving children and parents knowledge, and giving advices related to the eating of appropriate amounts from each food group everyday, to the eating breakfast, to the eating of healthy snacks, to reduction of fat intake, avoiding foods with saturated and trans fats, as well as to the drink plenty of water and reduction of foods and beverages high in added sugar. In nutrition, the project was comprised of two components: C1) Three nutrition individual meetings for children and parents or legal guardians; C2) Six nutrition educational lessons for children.

In the first meeting, the nutritionist assessed the food intake, the eating behaviour, and applied the 24-hours recall. In the second meeting ( $1^{\text {st }}$ month $)$, considering the interpretation of the information provided by the questionnaires, the nutritionist gave advices and developed an individualized dietary plan for healthy weight management based on baseline body size, energy requirements for growth, and PA level ${ }^{4}$. In the third meeting, after three month's intervention, the aim was to provide information about the anthropometric measures (AM) and change eating plan if necessary, as well as to give new advices about eating behaviour and food frequency. Furthermore, in the six nutrition educational sessions (one per month) in small groups a trained expert did activities to improve knowledge in order to change daily wrong behaviours. It was defined a specific subject matter and related tasks: Session 1: Top 10 of Healthy eating; Session 2: The food wheel; Session 3: Kings' Breakfast; Session 4: Colored Nutrition: Vegetables and Fruits - The healthy sweets; Session 5: Drinks and Sugar; Session 6: Red the labels.

Participant's attendance was monitored by the research team in all sessions.

During the intervention period, the participants of the $C G$ had two physical education classes according to normal curricula and normal school activities. The participants on the CG had access to the intervention after the trial.

\section{Measurements}

The main baseline variables were objectively measured. Blood sampling was taken in the Private Hospital Algarve Laboratory by a qualified phlebotomist experienced in paediatric sampling techniques, in order to assess the following blood parameters: glucose, TC, HDL-C, LDL-C, and TG. Blood samples were carried out at baseline and after six months through an intravenous way taken from the antecubital vein between 9:00 AM and 10:30 $\mathrm{AM}$, after a 12 hours overnight fast. For fasting blood glucose, $70-110 \mathrm{mg} / \mathrm{dl}$ was the reference desirable interval used. The following plasma lipid and lipoprotein concentrations $(\mathrm{mg} / \mathrm{dl})$ for children were used ${ }^{4}$ : TC (acceptable: $<170$; borderline-high: 170199; high: $\geq 200$ ); HDL-C (acceptable: $>45$; borderline-high: 40-45; high: < 40); LDL-C (acceptable: < 110; borderline-high: 110-129; high: $\geq 130$ ); TG (acceptable: $<75$; borderline-high: 75-99; high: $\geq 100$, for $0-9$ years of age); TG (acceptable: $<90$; borderline-high: 90-129; high: $\geq 130$, for $10-19$ years of age).

At baseline the height was measured to the nearest $0.1 \mathrm{~cm}$ with a fixed stadiometer (Seca 206), using standardized procedures. Body weight was measured to the nearest $0.1 \mathrm{~kg}$ using an electronic scale (Omron BF511T) with the participants wearing light sports clothing and no shoes. Overweight and obesity were 
determined according specific cut-offs $\mathrm{s}^{25}$. WC was measured with a flexible tape, above the iliac crest at the end of a gentle expiration, and classified according specific cut-offs ${ }^{26}$. The WHtR was calculated as the ratio of waist and height and was classified according the value of $\geq 0.5^{27}$. The same procedures were used three and six months later.

For resting BP, at baseline, after three and after six months, triplicate measurements were taken on the arm using a digital sphygmomanometer (Hartmann Tensoval Duo Control), an instrument clinically and scientifically validated ${ }^{28}$. Standardized procedures were performed, including the use of a paediatric sized cuff ${ }^{29,30}$. In each assessment, the $1^{\text {st }}$ measurement was not considered and mean value of $2^{\text {nd }}$ and $3^{\text {rd }}$ measurements of systolic blood pressure (SBP) and diastolic blood pressure (DBP) was calculated and used for the data analysis. The same procedures were used three and six months later.

CRF was assessed using the progressive aerobic cardiovascular endurance run (20-m shuttle run test $)^{31,32}$. The test was applied within the boundaries of standardized procedures, namely after a warm-up. A educational session was held to explain the test goals and rules and to allow a practical experience. $\mathrm{VO}_{2} \max$ was estimated by Matsuzaka et al.'s model ${ }^{33}$. The same test was applied three and six months later.

Habitual free-living PA and SB were objectively measured at baseline through accelerometers (ActiGraph GT3x, ActiLife 6.5.1 software). To assess short duration PA a 10 seconds epoch was used ${ }^{34}$. Researchers placed the accelerometer to the children's dominant waist, over or under clothing. Children and parents received a brochure about accelerometer use instructions. Participants wore accelerometers over 7 consecutive days, 5 weekdays and 2 weekend days. Researchers called and asked the teachers one day before collecting the devices to remind children to bring back to school. For data processing, a wear time validation criteria was applied: 10 hours during weekdays, and 8 hours on weekend days to ensure good compliance and more accurate outcomes ${ }^{35,36}$. Minutes per day of SB, LPA, MPA and VPA were estimated ${ }^{37,38}$. A sedentary bout was defined as 1 or more consecutive minutes with less than 100 counts/minute. The number of daily bouts of sedentary time lasting 1-4, 5-9, 10-14, 15-29, and 30+ minutes were calculated. Breaks in SB were calculated as any interruption lasting one minute or longer in which the accelerometer counts per minute rose up to or above $100^{39}$. The SB related to the small screen recreation was assessed through ASAQ, combining objective and self-report methods ${ }^{40}$.

Children's dietary intake was estimated with parents reporting children's diets as proxies. Food intake was assessed by the Semi-Quantitative Food Frequency Questionnaire ${ }^{41}$ and the main data were presented in calories ( $\mathrm{kcal})$, carbohydrates $(\mathrm{g})$, proteins $(\mathrm{g})$, lipids ( $\mathrm{g}$ ) soft drinks (ml), and high energy density (HED) snacks (g). The Child Eating Behaviour Questionnaire ${ }^{42-44}$ was also applied at baseline together with the 24-hours recall ${ }^{45}$. The 24-hours recall administration was not done place on Mondays in order to avoid that weekend days were reported in answering.

The following topics were addressed during the nutrition assessment: frequency of eating fast food or outside the home in restaurants, usual daily intake of sugar-sweetened beverages and $100 \%$ fruit juice typical portion sizes, frequency of eating breakfast, usual daily intake of foods that are high in energy density, usual intake of fruits and vegetables and meal frequency and snacking patterns ${ }^{1}$. Another questionnaire with specific information was applied to use in futures studies: 1) Pregnancy history; 2) Previous anthropometric data on appropriate growth charts; 3) Grand-parental, parental, and sibling anthropometrics; 4) Grand-parental, parental and sibling health conditions; 5) Use of medications by the child ${ }^{2}$.

After intervention, the Semi-Quantitative Food Frequency Questionnaire, the Child Eating Behaviour Questionnaire, and the 24-hours recall were applied.

All laboratory data, and administrative forms were identified by a coded ID [identification] number only to maintain participant confidentiality. All records that contain names or personal identifiers (locator forms and informed consent forms) will be stored separately from study records identified through code number. All databases will be secured with password protected access systems. Forms, lists, appointment books, and any other listings that link participant ID numbers to other identifying information were stored in a separate, locked file in an area with limited access ${ }^{46}$.

\section{Statistical analysis}

Statistical analysis were performed using IBM SPSS Statistics version 21. Descriptive analyses, including means and standard deviations were calculated. Significance level of set for $p$-value $<0.05$. Data distribution was initially examined for normality using the Shapiro-Wilk test. Partial correlations were performed on the entire data set to evaluate the strength of relationships between variables. Correlation coefficients were classified according Cohen's criterion $(\text { small }=.10 ; \text { medium }=.30 \text {; large }=.50)^{47}$. The $\mathrm{R}^{2}$ was used for the correlations' effect size ${ }^{48}$. ANCOVA (analysis of covariance) was used for the comparative analysis, using age and SES as covariates. Effect sizes were calculated for the ANCOVA and expressed as partial eta squared $(.01=$ small effect; $.06=$ medium effect; and $.14=$ large effect $)^{49,50}$. Considering clinical and statistical assumptions, effect sizes $>0.5$ indicate clinically relevant changes ${ }^{47}$.

The estimated number of participants needed to achieve objectives was determined through $\mathrm{G}^{*}$ Power 3.1 software. For a medium effect size in the $\mathrm{EG}$ of $\mathrm{d}=0.5$, power of .95 , signifying a $95 \%$ probability of reaching significance at the $\mathrm{p}=.05$ level), this is achieved with a group size of 30 participants. Assumed a $30 \%$ drop-out rate, this required an initial recruitment of 39 participants.

\section{Results}

The preceding section outlined the methods for all data collection throughout the Project PANK. Considering the restrictions of space, in results section, we only focus on some baseline results.

Table I provides descriptive statistics of blood variables, AM, BP, nutrition, SB, PA, and CRF. Regarding blood variables, $21.8 \%$ of the children had a borderline-high TC and $7.7 \%$ had a high value, $7.7 \%$ had a borderline-high HDL-C and $6.4 \%$ had 
a high value, $7.7 \%$ had a borderline-high LDL-C and $6.4 \%$ had a high value, and $9 \%$ had a borderline-high TG and $9 \%$ had a high value.

Furthermore, the sample comprised $5(6.5 \%)$ normal weight children, 32 (41.6\%) with overweight status and 40 (51.9\%) with obese status (recall that one of the study inclusion criteria was the presence of a metabolic risk factor). A total of 39 (50.6\%) children had normal WC and the prevalence of children with a high WC, usually associated with increased cardiovascular risk factors and IR, was $49,4 \%$. More than half of the participants $(77.9 \%$ ) had a WHtR larger than 0.5 (at risk) and $22.1 \%$ smaller than 0.5. The baseline participants data also showed that $75.3 \%$ did not met the current PA recommendations and only 19 participants (24.7\%) met 60 minutes of MVPA per day. The children spent, on average, more than 8 hours/day in SB $(513.62 \pm 65.19 \mathrm{~min} /$ day $)$.

Table I. Descriptive characteristics of the study sample.

\begin{tabular}{|c|c|c|c|}
\hline & Mean \pm SD & $\begin{array}{l}\text { Mini- } \\
\text { mum }\end{array}$ & $\begin{array}{l}\text { Maxi- } \\
\text { mum }\end{array}$ \\
\hline Age (years) & $8.78 \pm .64$ & 7 & 10 \\
\hline \multicolumn{4}{|c|}{ Blood Variables } \\
\hline Glucose (mg/dl) & $81.96 \pm 5.67$ & 61 & 96 \\
\hline $\begin{array}{l}\text { Total Cholesterol } \\
(\mathrm{mg} / \mathrm{dl})\end{array}$ & $159.84 \pm 26.77$ & 97 & 253 \\
\hline $\begin{array}{l}\text { HDL-Cholesterol } \\
(\mathrm{mg} / \mathrm{dl})\end{array}$ & $55.63 \pm 11.70$ & 35 & 85 \\
\hline $\begin{array}{l}\text { LDL-Cholesterol } \\
(\mathrm{mg} / \mathrm{dl})\end{array}$ & $90.22 \pm 22.10$ & 38 & 155 \\
\hline Triglycerides (mg/dl) & $65.37 \pm 26.69$ & 35 & 176 \\
\hline \multicolumn{4}{|c|}{ Anthopometric Measures } \\
\hline Weight (kg) & $40.75 \pm 3.55$ & 27.60 & 58.80 \\
\hline Height $(\mathrm{cm})$ & $1.38 \pm .06$ & 1.24 & 1.56 \\
\hline BMI z-score & $1.91 \pm .69$ & .22 & 3.62 \\
\hline $\begin{array}{l}\text { Waist circumference } \\
(\mathrm{cm})\end{array}$ & $73.88 \pm 7.60$ & 59 & 94 \\
\hline Waist-to-height ratio & $.53 \pm .05$ & .44 & .68 \\
\hline \multicolumn{4}{|c|}{ Blood Pressure } \\
\hline $\mathrm{SBP}(\mathrm{mmHg})$ & $85.62 \pm 7.47$ & 71 & 105 \\
\hline $\mathrm{DBP}(\mathrm{mmHg})$ & $60.95 \pm 7.93$ & 42 & 82 \\
\hline \multicolumn{4}{|c|}{ Nutrition } \\
\hline Calories (Kcal) & $2475.01 \pm 1111.61$ & 322.66 & 5493.93 \\
\hline Carbohydrates (g) & $323.21 \pm 149.39$ & 128.58 & 832.66 \\
\hline Proteins (g) & $118.47 \pm 76.97$ & 48.01 & 537.86 \\
\hline Lipids (g) & $90.12 \pm 40.81$ & 31.52 & 207.85 \\
\hline Soft drinks (ml) & $255.90 \pm 306.93$ & .00 & 1730.14 \\
\hline HED Snacks (g) & $102.71 \pm 124.26$ & .00 & 689.77 \\
\hline
\end{tabular}

\begin{tabular}{|c|c|c|c|}
\hline \multicolumn{4}{|c|}{ Sedentary Behaviour } \\
\hline $\begin{array}{l}\text { Sedentary Time ( } \mathrm{min} / \\
\text { day) }\end{array}$ & $513.90 \pm 65.19$ & 301.44 & 680.31 \\
\hline $\begin{array}{l}\text { Sedentary Bouts } 1-4 \\
\min (n / d)\end{array}$ & $158.10 \pm 19.90$ & 104.50 & 201.86 \\
\hline $\begin{array}{l}\text { Sedentary Bouts 5-9 } \\
\min (n / d)\end{array}$ & $26.26 \pm 7.36$ & 11.40 & 43.29 \\
\hline $\begin{array}{l}\text { Sedentary Bouts } \\
10-14 \min (\mathrm{n} / \mathrm{d})\end{array}$ & $8.41 \pm 3.36$ & 2.00 & 17.14 \\
\hline $\begin{array}{l}\text { Sedentary Bouts } \\
15-29 \min (\mathrm{n} / \mathrm{d})\end{array}$ & $3.36 \pm 1.62$ & .50 & 8.40 \\
\hline $\begin{array}{l}\text { Sedentary Bouts } 30+ \\
\min (n / d)\end{array}$ & $.71 \pm .47$ & .00 & 2.00 \\
\hline $\begin{array}{l}\text { SSR (week min/day) } \\
\text { SSR (weekend min/ } \\
\text { day) }\end{array}$ & $\begin{array}{c}127.71 \pm 72.65 \\
274.55 \pm 117.26\end{array}$ & $\begin{array}{c}0.00 \\
60.00\end{array}$ & $\begin{array}{l}453.00 \\
660.00\end{array}$ \\
\hline \multicolumn{4}{|c|}{ Physical Activity } \\
\hline LPA (min/day) & $220.53 \pm 33.21$ & 112.28 & 291.43 \\
\hline MPA (min/day) & $33.00 \pm 10.97$ & 10.76 & 58.33 \\
\hline VPA (min/day) & $15.02 \pm 7.88$ & 4.17 & 35.25 \\
\hline MVPA (min/day) & $48.02 \pm 18.00$ & 14.93 & 90.28 \\
\hline $\begin{array}{l}\text { Breaks in Sedentary } \\
\text { Time to LPA }(\mathrm{n} / \mathrm{d})\end{array}$ & $47.27 \pm 10.50$ & 18.67 & 70.00 \\
\hline $\begin{array}{l}\text { Breaks in Sedentary } \\
\text { Time to MPA }(n / d)\end{array}$ & $2.21 \pm 1.95$ & .00 & 8.43 \\
\hline $\begin{array}{l}\text { Breaks in Sedentary } \\
\text { Time to VPA }(n / d)\end{array}$ & $.97 \pm 1.06$ & .00 & 5.00 \\
\hline $\begin{array}{l}\text { MVPA Bouts 1-5 min } \\
(\mathrm{n} / \mathrm{d})\end{array}$ & $7.41 \pm 4.75$ & .80 & 21.43 \\
\hline $\begin{array}{l}\text { MVPA Bouts 6-10 } \\
\min (n / d)\end{array}$ & $.12 \pm .23$ & .00 & 1.43 \\
\hline $\begin{array}{l}\text { Cardiorespiratory } \\
\text { Fitness }\end{array}$ & $41.75 \pm 3.55$ & 33.22 & 49.79 \\
\hline
\end{tabular}

SD: Standard deviation;BMI:Body mass index;LPA:Lightphysical activity;MPA: Moderate physical activity; VPA: Vigorous physical activity; MVPA: Moderateto-vigorous physical activity; (n/d): Number/day; SB: Sedentary behaviour; SSR: Small Screen Recreation; SBP: Systolic blood pressure; DBP: Diastolic blood pressure; TC; HDL: High-density lipoprotein; LDL: Low-density lipoprotein; HED: High energy density; kcal (kilocalories); g (grams); ml (milliliters).

The comparative analysis by sex of AM, BP, nutrition, SB, PA, and CRF are presented in Table II. No differences were found in all blood variables between boys and girls, with the exception of TG. In fact, the girls presented higher TG levels when compared with boys. Regarding the PA, the boys presented higher levels of MPA, VPA, MVPA, and a higher number of 1-5 minutes MVPA bouts when compared with girls. On CRF, boys presented also a higher level, when compared with girls. No differences were found between sexes in AM, BP, SB, and in nutrition.

Comparing children with different weight status, a higher CRF was observed in overweight children, when compared with obese children. No other differences were observed according to weight status. 
Table II. Comparative analysis of anthropometric measures, cardiorespiratory fitness, physical activity, sedentary behaviours and blood pressure of the total sample according to sex.

\begin{tabular}{|c|c|c|c|c|c|}
\hline & $\begin{array}{c}\text { Boys } \\
(\mathrm{N}=46)\end{array}$ & $\begin{array}{c}\text { Girls } \\
(\mathbf{N}=\mathbf{3 1})\end{array}$ & & & \\
\hline & Mean \pm SD & Mean \pm SD & $\mathbf{F}$ & $\mathbf{\eta}_{\mathrm{p}}{ }^{2}$ & $\mathbf{p}$ \\
\hline \multicolumn{6}{|c|}{ Blood Variables } \\
\hline Glucose (mg/dl) & $81.82 \pm 6.14$ & $82.18 \pm 4.91$ & .07 & .001 & .789 \\
\hline $\begin{array}{l}\text { Total Cholesterol } \\
(\mathrm{mg} / \mathrm{dl})\end{array}$ & $\begin{array}{c}155.91 \pm \\
25.89\end{array}$ & $\begin{array}{l}166.14 \pm \\
27.43\end{array}$ & 1.10 & .028 & .162 \\
\hline $\begin{array}{l}\text { HDL-Cholesterol } \\
\text { (mg/dl) }\end{array}$ & $\begin{array}{c}56.29 \pm \\
11.63\end{array}$ & $\begin{array}{c}54.57 \pm \\
11.84\end{array}$ & .558 & .008 & .457 \\
\hline $\begin{array}{l}\text { LDL-Cholesterol } \\
\text { (mg/dl) }\end{array}$ & $\begin{array}{c}87.76 \pm \\
22.37\end{array}$ & $\begin{array}{c}94.33 \pm \\
21.42\end{array}$ & 1.03 & .015 & .313 \\
\hline $\begin{array}{l}\text { Triglycerides } \\
\text { (mg/dl) }\end{array}$ & $\begin{array}{c}58.47 \pm \\
24.62\end{array}$ & $\begin{array}{c}76.46 \pm \\
26.54\end{array}$ & 10.56 & .133 & .002 \\
\hline \multicolumn{6}{|c|}{ Anthopometric Measures } \\
\hline Weight (kg) & $41.20 \pm 6.10$ & $39.95 \pm 6.83$ & .945 & .013 & .334 \\
\hline Height (cm) & $1.39 \pm .06$ & $1.37 \pm .06$ & 1.34 & .018 & .251 \\
\hline BMI z-score & $1.99 \pm .68$ & $1.78 \pm .69$ & 3.38 & .044 & .070 \\
\hline $\begin{array}{l}\text { Waist circumfer- } \\
\text { ence }(\mathrm{cm})\end{array}$ & $73.57 \pm 7.83$ & $74.34 \pm 7.3$ & .001 & .000 & .977 \\
\hline $\begin{array}{l}\text { Waist-to-height } \\
\text { ratio }\end{array}$ & $.53 \pm .05$ & $.54 \pm .05$ & .403 & .005 & .527 \\
\hline \multicolumn{6}{|c|}{ Blood Pressure } \\
\hline $\mathrm{SBP}(\mathrm{mmHg})$ & $85.52 \pm 7.39$ & $85.76 \pm 7.70$ & .226 & .003 & .636 \\
\hline $\mathrm{DBP}(\mathrm{mmHg})$ & $60.80 \pm 8.04$ & $61.16 \pm 7.89$ & .309 & .004 & .580 \\
\hline \multicolumn{6}{|c|}{ Nutrition } \\
\hline Calories (Kcal) & $\begin{array}{c}2614.08 \pm \\
1068.91\end{array}$ & $\begin{array}{c}2286.27 \pm \\
1159.67\end{array}$ & .595 & .01 & .443 \\
\hline Carbohydrates (g) & $\begin{array}{c}346.66 \pm \\
143.14\end{array}$ & $\begin{array}{c}291.38 \pm \\
154.35\end{array}$ & 1.29 & .02 & .261 \\
\hline Proteins (g) & $\begin{array}{l}126.02 \pm \\
83.22\end{array}$ & $\begin{array}{c}108.22 \pm \\
67.69\end{array}$ & .611 & .01 & .438 \\
\hline Lipids (g) & $\begin{array}{c}96.54 \pm \\
39.95 \\
\end{array}$ & $\begin{array}{c}81.42 \pm \\
41.06\end{array}$ & 1.02 & .02 & .317 \\
\hline Soft drinks (ml) & $\begin{array}{c}297.25 \pm \\
159.82\end{array}$ & $\begin{array}{c}194.54 \pm \\
110.12\end{array}$ & 1.67 & .02 & .20 \\
\hline HED Snacks (g) & $\begin{array}{c}117.81 \pm \\
132.29\end{array}$ & $\begin{array}{l}80.30 \pm \\
108.65\end{array}$ & 1.50 & .02 & .23 \\
\hline \multicolumn{6}{|c|}{ Sedentary Behaviour } \\
\hline $\begin{array}{l}\text { Sedentary Time } \\
\text { (min/day) }\end{array}$ & $\begin{array}{c}517.26 \pm \\
63.78 \\
\end{array}$ & $\begin{array}{c}508.91 \pm \\
67.99 \\
\end{array}$ & .307 & .004 & .581 \\
\hline $\begin{array}{l}\text { Sedentary Bouts } \\
1-4 \mathrm{~min}(\mathrm{n} / \mathrm{d})\end{array}$ & $\begin{array}{l}158.78 \pm \\
19.40\end{array}$ & $\begin{array}{c}157.09 \pm \\
20.90\end{array}$ & 0.20 & .003 & .658 \\
\hline $\begin{array}{l}\text { Sedentary Bouts } \\
5-9 \min (\mathrm{n} / \mathrm{d})\end{array}$ & $26.89 \pm 7.18$ & $25.33 \pm 7.64$ & .908 & .012 & .344 \\
\hline
\end{tabular}

\begin{tabular}{|c|c|c|c|c|c|}
\hline $\begin{array}{l}\text { Sedentary Bouts } \\
10-14 \mathrm{~min}(\mathrm{n} / \mathrm{d})\end{array}$ & $8.62 \pm 3.38$ & $8.10 \pm 3.35$ & .41 & .006 & .522 \\
\hline $\begin{array}{l}\text { Sedentary Bouts } \\
15-29 \mathrm{~min}(\mathrm{n} / \mathrm{d})\end{array}$ & $3.43 \pm 1.64$ & $3.26 \pm 1.61$ & .21 & .003 & .652 \\
\hline $\begin{array}{l}\text { Sedentary Bouts } \\
30+\min (n / d)\end{array}$ & $.75 \pm .50$ & $.64 \pm .42$ & .64 & .009 & .427 \\
\hline $\begin{array}{l}\text { SSR (week min/ } \\
\text { day) }\end{array}$ & $\begin{array}{c}137.20 \pm \\
80.24\end{array}$ & $\begin{array}{l}113.65 \pm \\
58.05\end{array}$ & .97 & .01 & .33 \\
\hline $\begin{array}{l}\text { SSR (weekend } \\
\mathrm{min} / \text { day) }\end{array}$ & $\begin{array}{c}274.57 \pm \\
124.36\end{array}$ & $\begin{array}{c}274.52 \pm \\
107.85\end{array}$ & .00 & .00 & .97 \\
\hline \multicolumn{6}{|c|}{ Physical Activity } \\
\hline LPA (min/day) & $\begin{array}{c}225.07 \pm \\
31.81\end{array}$ & $\begin{array}{r}213 . \& \\
34 .\end{array}$ & 2.39 & .032 & .126 \\
\hline MPA (min/day) & $\begin{array}{c}36.91 \pm \\
10.51\end{array}$ & $27.21 \pm 8.99$ & 12.43 & .145 & .001 \\
\hline VPA (min/day) & $17.32 \pm 8.15$ & $11.61 \pm 6.12$ & 6.65 & .084 & .012 \\
\hline MVPA (min/day) & $\begin{array}{c}54.23 \pm \\
17.66\end{array}$ & $\begin{array}{c}38.81 \pm \\
14.39\end{array}$ & 10.90 & .130 & .001 \\
\hline $\begin{array}{l}\text { Breaks in Seden- } \\
\text { tary Time to LPA } \\
(\mathrm{n} / \mathrm{d})\end{array}$ & $\begin{array}{c}48.74 \pm \\
10.10\end{array}$ & $45.18 \pm 9.47$ & 2.61 & .034 & .111 \\
\hline
\end{tabular}

\section{Breaks in Seden-}

$\begin{array}{llllll}\text { tary Time to MPA } & 2.37 \pm 1.91 & 1.86 \pm 1.82 & .56 & .008 & .46\end{array}$ $(\mathrm{n} / \mathrm{d})$

Breaks in Seden-

$\begin{array}{llllll}\text { tary Time to VPA } & 1.09 \pm 1.18 & .78 \pm .81 & .53 & .007 & .470\end{array}$ $(\mathrm{n} / \mathrm{d})$

\begin{tabular}{llllll}
\hline MVPA Bouts 1-5 & $8.68 \pm 4.94$ & $5.53 \pm 3.78$ & 5.20 & .067 & .025
\end{tabular} $\min (\mathrm{n} / \mathrm{d})$

$\begin{array}{llllll}\text { MVPA Bouts } & .14 \pm .27 & .09 \pm .16 & .19 & .003 & .665 \\ 6-10 \mathrm{~min}(\mathrm{n} / \mathrm{d}) & & & \end{array}$
\begin{tabular}{llllll}
\hline $\begin{array}{l}\text { Cardiorespira- } \\
\text { tory fitness }\end{array}$ & $42.96 \pm 3.40$ & $39.96 \pm 3.01$ & 23.12 & .24 & .000
\end{tabular}

Note. a) Covariates: age and socioeconomic status (SES); SD: Standard deviation; BMI: Body mass index; LPA: Light physical activity; MPA: Moderate physical activity; VPA: Vigorous physical activity; MVPA: Moderateto-vigorous physical activity; SB: Sedentary behaviour; SSR: Small Screen Recreation; (n/d): Number/day; SBP: Systolic blood pressure; DBP: Diastolic blood pressure; HED: High energy density; np2: Partial Eta Squared; kcal (kilocalories); g (grams); ml (milliliters).

Partial correlation between blood variables and BP with AM, $\mathrm{SB}, \mathrm{PA}$, and CRF is presented in Table III (age, sex and SES as covariates). The BMI z-score, the WC, and the WHtR were all positively associated with TG levels (all $\mathrm{p} \leq .002$ ). BMI $\mathrm{z}$-score $(\mathrm{p}=.014)$, and WHtR $(\mathrm{p}=.027)$ were positively associated with glucose levels. Only BMI Z-score was positively associated with $\operatorname{SBP}(p=.022)$.

On nutrition data, it was found a positive association between LDL-C levels and both calories ingested $(\mathrm{p}=.048)$ and lipids $(p=.045)$. The intake of soft drinks was positively associated with glucose levels $(p=.02)$. Caloric intake was also positively associated with BMI z-score $(\mathrm{p}=.046)$, with WC $(\mathrm{p}=.049)$, and with WHtR $(p=.033)$. A similar pattern of associations were observed between lipids and BMI z-score $(p=.027), W C(p=.022)$, and WHtR $(\mathrm{p}=.034)$. The week SSR was positively associated 
with calories $(\mathrm{p}=.005)$, with carbohydrates $(\mathrm{p}=.011)$, and with lipids ingested $(\mathrm{p}=.011)$. No associations were found between macronutrients and caloric intake and PA or CRF.

SB was not associated with blood variables or BP. In opposition, the length of time spent in LPA was positively associated with HDL-C $(\mathrm{p}=.013)$ and with $\operatorname{DBP}(\mathrm{p}=.045)$, and the number of breaks to do LPA was positively associated with SBP and DBP.

A significant inverse relationship between $\mathrm{CRF}$ and TG levels was also found $(p \leq .001)$. However, no associations were found between CRF and SBP or DBP.

Furthermore, other partial correlations showed no associations between blood variables and BP. Similar results were found between all SB data and CRF.
Only VPA $(p=.010)$ and MVPA $(p=.032)$ were positively associated with CRF. The MPA $(p=.001), \operatorname{VPA}(p=.013)$ and $\operatorname{MVPA}(p=.002)$ were all inversely associated with the length of time spent in SB. The same was verified for total SB bouts 1-4 minutes with MPA, with VPA, and with MVPA (all $\mathrm{p} \leq .005$ ). The number of 5-9 minutes sedentary bouts was inversely associated with all PA levels (all $\mathrm{p} \leq .018$ ). The number of 10-14 minutes sedentary bouts was negatively associated with LPA, MPA, and MVPA (all $\mathrm{p} \leq .007$ ). Similar results were verified between the number of 15-29 minutes sedentary bouts and LPA, MPA, and MVPA (all $p \leq .015$ ). The number of $30+$ minutes sedentary bouts was negatively associated with MPA, VPA, and MVPA (all $\mathrm{p} \leq .032$ ).

Table III. Partial correlation between blood variables and blood pressure with anthropometric variables, sedentary behaviour, physical activity, and cardiorespiratory fitness (controlled for sex, age, and socioeconomic status)

\begin{tabular}{|c|c|c|c|c|c|c|c|c|c|c|c|c|c|c|}
\hline & \multicolumn{2}{|c|}{ Glucose } & \multicolumn{2}{|c|}{ Total Cholesterol } & \multicolumn{2}{|c|}{ HDL-C } & \multicolumn{2}{|c|}{ LDL-C } & \multicolumn{2}{|c|}{ TG } & \multicolumn{2}{|c|}{ SBP } & \multicolumn{2}{|c|}{ DBP } \\
\hline & $\mathbf{r}$ & $\mathbf{p}$ & $\mathbf{r}$ & $\mathbf{p}$ & $\mathbf{r}$ & $\mathbf{p}$ & $\mathbf{r}$ & $\mathbf{p}$ & $\mathbf{r}$ & $\mathbf{p}$ & $\mathbf{r}$ & $\mathbf{p}$ & $\mathbf{r}$ & $\mathbf{p}$ \\
\hline \multicolumn{15}{|c|}{ Anthopometric Measures } \\
\hline BMI z-score & .296 & .014 & .089 & .465 & -.134 & .271 & .099 & .417 & .366 & .002 & .275 & .022 & .215 & .076 \\
\hline $\begin{array}{l}\text { Waist circumference } \\
(\mathrm{cm})\end{array}$ & .214 & .077 & .061 & .617 & -.171 & .160 & .076 & .535 & .421 & $<.001$ & .207 & .089 & .167 & .171 \\
\hline Waist-to-height ratio & .266 & .027 & .144 & .237 & -.168 & .168 & .158 & .196 & .471 & $<.001$ & .177 & .145 & 1.73 & .156 \\
\hline \multicolumn{15}{|c|}{ Nutrition } \\
\hline Calories (kcal) & -.067 & .613 & .238 & .070 & .011 & .935 & .259 & .048 & .050 & .709 & .035 & .787 & -.138 & .281 \\
\hline Carbohydrates (g) & -.039 & .768 & .177 & .179 & .037 & .779 & .176 & .182 & .048 & .720 & -.069 & .593 & -.230 & .070 \\
\hline Proteins (g) & .119 & .369 & .183 & .166 & .063 & .633 & .205 & .119 & -.133 & .317 & -.032 & .802 & -.143 & .263 \\
\hline Lipids (g) & .009 & .946 & .243 & .063 & .243 & .063 & .262 & .045 & .059 & .656 & .070 & .585 & -.129 & .315 \\
\hline Soft drinks (ml) & .277 & .020 & .054 & .656 & .117 & .334 & -.019 & .876 & .067 & .581 & -.047 & .694 & -.255 & .028 \\
\hline HED Snacks (g) & .004 & .975 & .215 & .076 & .192 & .114 & .134 & .274 & .072 & .577 & .133 & .275 & -.078 & .526 \\
\hline \multicolumn{15}{|c|}{ Sedentary Behaviour } \\
\hline $\begin{array}{l}\text { Sedentary Time } \\
(\mathrm{min} / \text { day })\end{array}$ & .218 & .072 & .120 & .326 & .190 & .118 & .055 & .652 & -.100 & .415 & -.132 & .281 & -.085 & .487 \\
\hline $\begin{array}{l}\text { Sedentary Bouts } 1-4 \\
\min (n / d)\end{array}$ & .188 & .122 & .134 & .273 & .097 & .429 & .114 & .350 & -.065 & .598 & -.204 & .093 & -.135 & .270 \\
\hline $\begin{array}{l}\text { Sedentary Bouts 5-9 } \\
\min (\mathrm{n} / \mathrm{d})\end{array}$ & .157 & .198 & .023 & .854 & .003 & .980 & .008 & .951 & .062 & .613 & -.057 & .643 & -.123 & .315 \\
\hline $\begin{array}{l}\text { Sedentary Bouts } \\
10-14 \min (\mathrm{n} / \mathrm{d})\end{array}$ & .153 & .210 & .023 & .849 & .053 & .666 & -.019 & .875 & .063 & .606 & -.050 & .682 & -.072 & .558 \\
\hline $\begin{array}{l}\text { Sedentary Bouts } \\
15-29 \min (\mathrm{n} / \mathrm{d})\end{array}$ & .159 & .191 & .040 & .745 & .023 & .852 & .025 & .839 & .028 & .818 & -.007 & .954 & -.024 & .844 \\
\hline $\begin{array}{l}\text { Sedentary Bouts } 30+ \\
\min (n / d)\end{array}$ & .167 & .171 & .180 & .139 & .162 & .185 & .088 & .472 & .118 & .335 & .051 & .676 & .207 & .087 \\
\hline SSR (week min/day) & -.134 & .273 & .042 & .735 & .065 & .598 & .024 & .845 & -.058 & .638 & .178 & .143 & .112 & .360 \\
\hline $\begin{array}{l}\text { SSR (Weekend } \mathrm{min} / \\
\text { day) }\end{array}$ & -.179 & .140 & -.046 & .708 & .073 & .551 & -.076 & .536 & -.091 & .456 & .103 & .400 & .177 & .145 \\
\hline
\end{tabular}




\begin{tabular}{|c|c|c|c|c|c|c|c|c|c|c|c|c|c|c|}
\hline LPA (min/day) & .031 & .800 & .072 & .555 & .296 & .013 & -.052 & .670 & -.111 & .362 & .139 & .253 & .242 & .045 \\
\hline MPA (min/day) & -.003 & .977 & -.168 & .168 & -.003 & .983 & -.167 & .170 & -.110 & .369 & .108 & .378 & .112 & .359 \\
\hline VPA (min/day) & -.096 & .432 & -.062 & .614 & .105 & .392 & -.102 & .403 & -.093 & .449 & .042 & .729 & .015 & .903 \\
\hline MVPA (min/day) & -.045 & .711 & -.127 & .297 & .046 & .709 & -.145 & .234 & -.107 & .382 & .083 & .497 & .073 & .550 \\
\hline $\begin{array}{l}\text { Breaks in Sedentary } \\
\text { Time to LPA }(\mathrm{n} / \mathrm{d})\end{array}$ & .033 & .791 & .033 & .788 & .204 & .092 & -.074 & .546 & -.001 & .993 & .243 & .044 & .265 & .028 \\
\hline $\begin{array}{l}\text { Breaks in Sedentary } \\
\text { Time to MPA }(n / d)\end{array}$ & .093 & .446 & -.177 & .146 & -.137 & .261 & -.111 & .365 & -.802 & .502 & .087 & .478 & .122 & .319 \\
\hline $\begin{array}{l}\text { Breaks in Sedentary } \\
\text { Time to VPA }(\mathrm{n} / \mathrm{d})\end{array}$ & -.028 & .817 & -.101 & .410 & .104 & .395 & -.158 & .195 & -.040 & .743 & .056 & .649 & .002 & .985 \\
\hline $\begin{array}{l}\text { MVPA Bouts 1-5 } \\
\min (n / d)\end{array}$ & -.041 & .739 & -.086 & .482 & .077 & .527 & -.111 & .363 & -.117 & .339 & .112 & .359 & .089 & .468 \\
\hline $\begin{array}{l}\text { MVPA Bouts 6-10 } \\
\min (\mathrm{n} / \mathrm{d})\end{array}$ & .151 & .216 & -.139 & .254 & -.030 & .804 & -.117 & .340 & -.114 & .351 & -.023 & .851 & .023 & .854 \\
\hline $\begin{array}{l}\text { Cardiorespiratory } \\
\text { Fitness }\end{array}$ & -.173 & .156 & -.155 & .202 & .136 & .265 & -.150 & .219 & -.471 & $<.001$ & -.183 & .132 & -.123 & .313 \\
\hline
\end{tabular}

SD: Standard deviation; BMI: Body mass index; LPA: Light physical activity; MPA: Moderate physical activity; VPA: Vigorous physical activity; MVPA: Moderateto-vigorous physical activity; SSR: Small Screen Recreation; (n/d): Number day; SBP: Systolic blood pressure; DBP: Diastolic blood pressure; HDL: High-density lipoproteins; LDL: Low-density lipoproteins; TG: Triglycerides; HED: High energy density; kcal (kilocalories); g (grams); ml (milliliters). Note: Covariates: age, sex and socioeconomic status (SES).

\section{Discussion}

This paper presents an overview of Project PANK. After the study protocol the main baseline results were presented. The main results related to the primary outcomes were: a) The BMI z-score, waist circumference, and waist-to-height ratio were all positively associated with triglycerides and caloric intake; b) Borderline and high triglycerides summed up to $18.0 \%$ of the children and borderline and high total cholesterol $29.5 \%$; c) The BMI z-score, waist-to-height ratio, and the ingestion of soft drinks were positively associated with glucose; d) The BMI z-score was positively associated with systolic blood pressure; e) The LDL-C was positively associated with caloric intake and lipids and similar associations were observed between lipids and BMI z-score.

The physical activity, sedentary behaviour, and cardiorespiratory fitness presented another set of results: f) Sedentary behaviour was not associated with blood variables or blood pressure; g) The week small screen recreation was positively associated with calories, carbohydrates, and lipids ingested; h) Light physical activity time was positively associated with $\mathrm{HDL}-\mathrm{C}$ and diastolic blood pressure and the number of breaks in sedentary time to light physical activity was positively associated with systolic and diastolic blood pressure; i) Moderate, vigorous, and moderate-to-vigorous physical activity were inversely associated with sedentary behaviour time and with several sedentary behaviour bouts; j) An inverse relationship between cardiorespiratory fitness and triglycerides was found, and only vigorous and moderate-to-vigorous physical activity was positively associated with cardiorespiratory fitness; k) No associations were found between cardiorespiratory fitness and blood pressure.

All the main results related the primary outcomes (blood variables, anthropometric measures, blood pressure and also nutrition) show that several variables contribute to the development of cardiovascular and metabolic risk factors in youth. Atherosclerosis begins in childhood and is associated with the presence and intensity of identified risk factors, such as blood lipids, overweight/obesity, high blood pressure, nutrition/diet ${ }^{4}$.

In fact, the overweight/obesity conditions are commonly associated with a combined dyslipidemia pattern, with mild elevations in total cholesterol and LDL-C, moderate to severe elevation in triglycerides, and low HDL- $\mathrm{C}^{4}$. In the present study, this dyslipidemia pattern was verified for total cholesterol and triglycerides. The positive associations between some of these cardiovascular and metabolic risk factors confirm one of the main research hypotheses.

The results indicating that $18.0 \%$ of the children had a borderline and high triglycerides and $29.5 \%$ had a borderline and high total cholesterol are consistent with recent findings. In the lowest estimated prevalence of European children with obesity-related disease indicators, $21.5 \%$ has raised triglycerides and $22.1 \%$ total cholesterol ${ }^{3}$.

Therefore, when elevated triglycerides are associated with obesity, decreased calorie intake and increased physical activity levels have paramount importance. The first step proposed for management of children with identified lipid abnormalities is a focused intervention to improve physical activity and $\operatorname{diet}^{4}$. Thus, these results can also be explained by the children's food intake and eating behaviour. In children with elevated triglycerides, weight loss and reduction of simple carbohydrate intake are associated with decreased triglycerides because these are very responsive to weight loss and diet composition ${ }^{4}$. Most importantly, in overweight and obese children with elevated triglycerides levels, even small amounts of weight loss are associated with significant decreases in triglycerides and increases in HDL-C ${ }^{4}$. 
However, considering the associations founded for the caloric intake, the ingestion of soft drinks and lipids, diet interventions must be comprehensive to be effective. In a multidisciplinary approach, a diet intervention is important because changes in the family food environment were associated with positive dietary change in children ${ }^{51}$. Additionally, young children tend to be the highest consumers of fruit juices, and some studies have noted associations between high juice consumption and obesity. Fruit juices and soft drinks have high amounts of sugar that children and parents are unaware. Increased sugar-sweetened beverage intake is associated with obesity in multiple reports ${ }^{4}$. Findings from a systematic review and meta-analysis of prospective cohort studies and randomized controlled trials provide evidence that sugar-sweetened beverages consumption promotes weight gain in children ${ }^{52}$. There is increasing concern that intake of free sugars - sugar-sweetened beverages - increases overall energy intake and may reduce the intake of foods containing more nutritionally adequate calories, leading to an unhealthy diet, weight gain and increased risk of noncommunicable diseases ${ }^{53}$.

Nevertheless, balancing energy intake with energy expenditure in a developing child is a complex process ${ }^{4}$. The increasing obesity prevalence in children reflects a chronic imbalance between energy intake and expenditure, where calorie intake is in excess of what is needed for normal growth ${ }^{1}$. Thus, although children need greater energy intake per kilogram of body weight than adults to accommodate the body's demands for growth, this must be balanced with physical activity needs ${ }^{4}$.

So, the results observed in physical activity, sedentary behaviour, and cardiorespiratory fitness highlights the importance of multidisciplinary interventions to promote the reversion of overweight/obesity conditions and to decrease abdominal fat in early ages. Strong evidence has shown that physical activity is associated with several health benefits ${ }^{9-11}$. Strong evidences purport that moderate-to-vigorous physical activity increases are associated with lower systolic and diastolic blood pressure, decreased body fat, body mass index, and insulin resistance, improved fitness, lower LDL-C, total cholesterol, and triglycerides, and higher HDL-C ${ }^{4}$. However, the participants' baseline data showed that $75.3 \%$ did not met the current physical activity recommendations and only 19 participants $(24.7 \%)$ met 60 minutes of moderate-to-vigorous physical activity per day. Results from the Energy-project indicated that a large proportion of European children does not meet the physical activity recommendations and exhibit prolonged sedentary behaviour ${ }^{6}$. Therefore, this result is in agreement with recent studies and confirms another research hypotheses.

Nevertheless, to achieve all the physical activity benefits, children should engage in moderate-to-vigorous physical activity for at least 60 minutes and up to several hours every day ${ }^{54}$. To maintain a healthy weight, additional physical activity may be required $^{12}$. Hence, our comprehensive physical activity intervention aims to enhance physical activity through everyday activity, active recreation and sport $^{54}$. Increasing physical activity seems probably important if we take into account the positive associations found between the time spent in light physical activity and the HDL-C.

Additionally, other results suggest that physical activity intensity is very important considering the positive associations between vigorous and moderate-to-vigorous physical activity and the cardiorespiratory fitness. It is known the effect of higher intensity aerobic physical activity in aerobic fitness levels ${ }^{55}$. Hence, increasing physical activity can play a relevant role in cardiorespiratory fitness improvements by the maximum oxygen consumption increasing, and both can have a clinical independent effect in triglycerides levels, through different pathways ${ }^{7}$. The increased faculty to use fat following endurance training results from an better capacity to mobilize free-fatty acids from fat depots and an improved ability to oxidize fat consequent to the increase in the muscle enzymes responsible for fat oxidation ${ }^{56}$. The negative relationship between cardiorespiratory fitness and triglycerides levels also corroborate these assumptions and confirm another research hypotheses based on the European Youth Heart Study ${ }^{55}$.

Furthermore, the inverse associations between moderate, vigorous, and moderate-to-vigorous physical activity with sedentary behaviour time and with several sedentary behaviour bouts show that physical activity interventions may be useful to decrease sedentary behaviour. This aim seems important because frequent interruptions in sedentary time were also associated with a favourable cardiometabolic risk profile and highlight the deleterious relationship between screen time and cardiometabolic risk among children with a family history of obesity ${ }^{13}$. Television viewing is the more prominent factor in terms of predicting overweight, and it contributes to obesity and the exposure to television might also impact body weight by promoting excess energy intake ${ }^{57}$. The positive association founded between week small screen recreation and the calories, carbohydrates, and lipids ingested confirm another research hypotheses. Thus, as a result of the mechanisms presented above, the multidisciplinary intervention designed seems appropriate considering the overall objective related to enhance of physical activity and decrease sedentary behaviour, improve cardiorespiratory fitness, change eating behaviour and food intake in order to improve glucose, total cholesterol, HDL-C, LDL-C, and triglycerides, as well as BMI z-score, waist circumference, waist-to-height ratio, and blood pressure ${ }^{11}$.

The findings from our study should be considered together with some limitations. Firstly, this is a cross-sectional study providing evidence for associations but not causation. Secondly, participants do not represent a large nationwide representative sample because all participants were only recruited from one Portuguese primary public urban school. Thirdly, the intervention included only some of the components of interventions efficacy suggested by the literature. Finally, this is only a 6-month multidisciplinary school-based intervention and a follow-up was not considered.

Concerning about the strengths, the objective measures of anthropometric measures from all participating children, as well as accelerometer measures of physical activity and sedentary behaviour and blood samples from respondents, further enriches the data set. All these measurements were obtained according to standard methodology and protocols in all participating. Can be regarded as a strength the number of physical activity and sedentary behaviour objectively assessments (one per month) by accelerometers throughout the intervention. The originality of the application of such an intervention in Portugal can also be regarded a strength. 


\section{Conclusions}

These baseline results justify the importance of multidisciplinary school-based interventions to promote the reversion of overweight/obesity conditions and to decrease abdominal fat clinically significant. For the main outcomes, we hypothesized that participants of the experimental group will improve blood variables, anthropometric measures and blood pressure after the intervention, when compared with control group. Considering recent findings, for the improvements mentioned we theorized that intervention design would enhance physical activity, decrease sedentary behaviour, and change eating behaviour in order to improve cardiorespiratory fitness. Project PANK focus on these modifiable behavioural risk factors in a comprehensive, multicomponent and significant curriculum in physical activity and nutrition programs, taught by trained experts, and a parental component. According final results is expected to provide useful guidance to researchers, public health professionals, and schoolteachers seeking to develop similar programs.

\section{Note}

This research protocol was written according SPIRIT 2013 Statement (Standard Protocol Items: Recommendations for Interventional Trials $)^{46}$.

\section{Trial Registration}

Portuguese Data Protection Committee (case No. 10221/2012, authorization No. 9130/2012) and Ministry of Education (survey No. 0339300001).

\section{References}

1. CDC. US Department of Health and Human Services. School Health Guidelines to Promote Healthy Eating and Physical Activity. 2011.

2. Baker J, Farpour-Lambert N, Nowicka P, Pietrobelli A, Weiss R. Evaluation of the overweight/obese child - practical tips for the primary health care provider: recommendations from the Childhood Obesity Task Force of the European Association for the Study of Obesity. Obes facts. 2010;3(2):131-7.

3. WHO. Report of the Commission on Ending Childhood Obesity. Geneva, Switzerland. 2016.

4. Daniels S, Irwin B, Christakis D, Dennison B, Gidding S, Gillman $\mathrm{M}$, et al. Expert Panel on Integrated Guidelines for Cardiovascular Health and Risk Reduction in Children and Adolescents. US Department of Health and Human Services. National Heart, Lung, and Blood Institute. NIH. 2012.

5. Pedrosa C, Oliveira BM, Albuquerque I, Simões-Pereira C, Vazde-Almeida MD, Correia F. Obesity and metabolic syndrome in 7-9 years-old Portuguese schoolchildren. Diabetol Metab Syndr. 2010;2(1):40.
6. Verloigne M, Van Lippevelde W, Maes L, Yıldırım M, Chinapaw M, Manios Y, et al. Levels of physical activity and sedentary time among 10 - to 12-year-old boys and girls across 5 European countries using accelerometers: an observational study within the ENERGY-project. IJBNPA. 2012;9:34.

7. Steele RM, Brage S, Corder K, Wareham NJ, Ekelund U. Physical activity, cardiorespiratory fitness, and the metabolic syndrome in youth. J of Appl Physiol. 2008;105(1):342-51.

8. Metcalf B, Henley W, Wilkin T. Effectiveness of intervention on physical activity of children: systematic review and metaanalysis of controlled trials with objectively measured outcomes (EarlyBird 54). Bmj. 2012;345:e5888.

9. CDC. US Department of Health and Human Services. Physical Activity Guidelines Advisory Committee Report. Washington, DC. 2008.

10. WHO. Global Recommendations on Physical Activity for Health. Switzerland 2010.

11. WHO. Interventions on Diet and Physical Activity. What Works. Summary Report. 2009.

12. Janssen I, Leblanc AG. Systematic review of the health benefits of physical activity and fitness in school-aged children and youth. IJBNPA. 2010;7:40.

13. Saunders TJ, Tremblay MS, Mathieu ME, Henderson M, O'Loughlin J, Tremblay A, et al. Associations of sedentary behaviour, sedentary bouts and breaks in sedentary time with cardiometabolic risk in children with a family history of obesity. PloS one. 2013;8(11):e79143.

14. Rezende LF, Rodrigues Lopes M, Rey-Lopez JP, Matsudo VK, Luiz Odo C. Sedentary behaviour and health outcomes: an overview of systematic reviews. PloS one. 2014;9(8):e105620.

15. McAleese JD, Rankin LL. Garden-based nutrition education affects fruit and vegetable consumption in sixth-grade adolescents. J Am Diet Assoc. 2007;107(4):662-5.

16. He M, Beynon C, Sangster Bouck M, St Onge R, Stewart S, Khoshaba L, et al. Impact evaluation of the Northern Fruit and Vegetable Pilot Programme - a cluster-randomised controlled trial. Public Health Nutr. 2009;12(11):2199-208.

17. Contento IR, Kell DG, Keiley MK, Corcoran RD. A formative evaluation of the American Cancer Society Changing the Course nutrition education curriculum. J Sch Health. 1992;62(9):411-6.

18. Dunton GF, Lagloire R, Robertson T. Using the RE-AIM framework to evaluate the statewide dissemination of a school-based physical activity and nutrition curriculum: "Exercise Your Options". Am J Health Promot. 2009;23(4):229-32.

19. Perez-Rodrigo C, Aranceta J. School-based nutrition education: lessons learned and new perspectives. Public Health Nutr. 2001;4(1A):131-9.

20. Shilts MK, Horowitz M, Townsend MS. Guided goal setting: effectiveness in a dietary and physical activity intervention with lowincome adolescents. Int J Adolesc Med Health. 2009;21(1):111-22.

21. Allensworth DD. The research base for innovative practices in school health education at the secondary level. J Sch Health. 1994;64(5):180-7.

22. Rickard KA, Gallahue DL, Gruen GE, Tridle M, Bewley N, Steele $\mathrm{K}$. The play approach to learning in the context of families and schools: an alternative paradigm for nutrition and fitness education in the 21st century. J Am Diet Assoc. 1995;95(10):1121-6. 
23. Tudor-Locke C, Craig CL, Beets MW, Belton S, Cardon GM, Duncan S, et al. How many steps/day are enough? for children and adolescents. IJBNPA. 2011;8:78.

24. Adams MA, Johnson WD, Tudor-Locke C. Steps/day translation of the moderate-to-vigorous physical activity guideline for children and adolescents. IJBNPA. 2013;10:49.

25. WHO. Child Growth Standards: Head circumference-for-age, arm circumference-for-age, triceps skinfold-for-age and subscapular skinfold-for-age: Methods and development. Multicentre Growth Reference Study Group Geneva. 2007.

26. Fernández JR, Redden DT, Pietrobelli A, Allison DB. Waist circumference percentiles in nationally representative samples of African-American, European-American, and Mexican-American children and adolescents. J Pediatr. 2004;145(4):439-44.

27. Nambiar S, Hughes I, Davies PS. Developing waist-to-height ratio cut-offs to define overweight and obesity in children and adolescents. Public Health Nutr. 2010;13(10):1566-74.

28. De Greeff A, Arora J, Hervey S, Liu B, Shennan AH. Accuracy assessment of the Tensoval duo control according to the British and European Hypertension Societies' standards. Blood Press Monit. 2008;13(2):111-6.

29. Cromwell PF, Munn N, Zolkowski-Wynne J, Department S-BHCDotBH. Evaluation and management of hypertension in children and adolescents (part one): diagnosis. J Pediatr Health Care. 2005;19(3):172-5.

30. US Department of Health and Human Services. National Heart L, and Blood Institute. National Institutes of Health. The Fourth Report on the Diagnosis, Evaluation, and Treatment of High Blood Pressure in Children and Adolescents. 2005.

31. Plowman S, Meredith, MD (Eds.). Fitnessgram/Activitygram Reference Guide (4th Edition). Dallas, TX: The Cooper Institute. 2013.

32. Léger LA, Mercier D, Gadoury C, J. L. The multistage 20 metre shuttle run test for aerobic fitness. J Sports Sci. 1988; 6:93-101.

33. Matsuzaka A, Takahashi Y, Yamazoe M, Kumakura N, Ikeda A, Wilk B, et al. Validity of the multistage $20-\mathrm{m}$ shuttle-run test for Japanese children, adolescents, and adults. Ped Ex Sci 2004; 16:113-25.

34. Kelli L, Cain M. International Physical Activity and the Environment Network. IPEN Adolescent Accelerometer Data Collection Training. 2014.

35. Cain KL, Sallis JF, Conway TL, Van Dyck D, Calhoon L. Using accelerometers in youth physical activity studies: a review of methods. J Phys Act Health. 2013;10(3):437-50.

36. Rich C, Geraci M, Griffiths L, Sera F, Dezateux C, Cortina-Borja M. Quality control methods in accelerometer data processing: defining minimum wear time. PloS one. 2013;8(6):e67206.

37. Evenson KR, Catellier DJ, Gill K, Ondrak KS, McMurray RG. Calibration of two objective measures of physical activity for children. J Sports Sci. 2008;26(14):1557-65.

38. Trost SG, Loprinzi PD, Moore R, Pfeiffer KA. Comparison of accelerometer cut points for predicting activity intensity in youth. Med Sci Sports Exerc.2011;43(7):1360-8.

39. Healy GN, Dunstan DW, Salmon J, Cerin E, Shaw JE, Zimmet PZ, et al. Breaks in sedentary time: beneficial associations with metabolic risk. Diabetes care. 2008;31(4):661-6.
40. Verloigne M, Loyen A, Van Hecke L, Lakerveld J, Hendriksen I, De Bourdheaudhuij I, et al. Variation in population levels of sedentary time in European children and adolescents according to cross-European studies: a systematic literature review within DEDIPAC. IJBNPA. 2016;13(1):69.

41. Lopes C. Reprodutibilidade e validação de um questionário de frequência alimentar Porto. Tese.[Tese de Doutoramento] Universidade do Porto. 2000.

42. Viana V, Sinde S, Saxton JC. Children's Eating Behaviour Questionnaire: associations with BMI in Portuguese children. Br J Nutr. 2008;100(2):445-50.

43. Wardle J, Guthrie CA, Sanderson S, Rapoport L. Development of the Children's Eating Behaviour Questionnaire. J Child Psychol Psychiatry. 2001;42(7):963-70.

44. Viana V, \& Sinde, S. Estilo Alimentar: Adaptação e validação do Questionário Holandês do Comportamento Alimentar. Psicologia: Teoria, Investigação e Prática. 2003; 8, 59-71.

45. Lytle LA, Nichaman MZ, Obarzanek E, Glovsky E, Montgomery D, Nicklas T, et al. Validation of 24-hour recalls assisted by food records in third-grade children. The CATCH Collaborative Group. J Am Diet Assoc. 1993;93(12):1431-6.

46. Chan AW, Tetzlaff JM, Gotzsche PC, Altman DG, Mann H, Berlin JA, et al. SPIRIT 2013 explanation and elaboration: guidance for protocols of clinical trials. Bmj. 2013;346:e7586.

47. Cohen J. Statistical Power Analysis for the Behavioral Sciences. (2nd ed.). Hillsdale: NJ: Lawrence Erlbaum Associates. 1998.

48. Field A. Discovering Statistics using SPSS. Third Edition. SAGE Publications Ltd. 2009.

49. Pallant J. SPSS survival manual. New York: McGraw-Hill Education. 2007.

50. Lakens D. Calculating and reporting effect sizes to facilitate cumulative science: a practical primer for t-tests and ANOVAs. Front Psychol. 2013;4:863.

51. Hendrie G, Sohonpal G, Lange K, Golley R. Change in the family food environment is associated with positive dietary change in children. IJBNPA. 2013;10:4.

52. Malik VS, Pan A, Willett WC, Hu FB. Sugar-sweetened beverages and weight gain in children and adults: a systematic review and meta-analysis. Am J Clin Nutr. 2013;98(4):1084-102.

53. World Health Organization. Guideline: Sugars intake for adults and children. 2015.

54. Star Active, Stay Active. A Report on Physical Activity for Health from the four home countries. Chief Medical Officers. 2011.

55. Andersen L, Sardinha LB, Froberg K, Riddoch CJ, Page AS, Anderssen SA. Fitness, fatness and clustering of cardiovascular risk factors in children from Denmark, Estonia and Portugal: the European Youth Heart Study. Int J Pediatr Obes 2008;3 Suppl 1:58-66.

56. Costill D, Kenney, L, Wilmore, J. Physiology of Sport and Exercise. 6th Edition. 2015.

57. Tudor-Locke C, Craig CL, Cameron C, Griffiths JM. Canadian children's and youth's pedometer-determined steps/day, parent-reported TV watching time, and overweight/obesity: the CANPLAY Surveillance Study. IJBNPA. 2011;8:66.

58. Clyburne-Sherin AV, Thurairajah P, Kapadia MZ, Sampson M, Chan WW, Offringa M. Recommendations and evidence for 
reporting items in pediatric clinical trial protocols and reports: two systematic reviews. Trials. 2015;16:417.

\section{Acknowledgments}

This work was supported by the Portuguese Science Foundation through individual research grant

(SFRH/BD/85518/2012) co-financed by the European Social Fund and Portuguese National Funds from MCTES

\section{Corresponding author}

Rui Batalau

Universidade Lusófona de Humanidades e Tecnologias - Faculdade de Educação Física e Desporto, Campo Grande Lisboa 1749-024, Portugal.

Email:ruibatalau@gmail.com

Manuscript received on December 10, 2016

Manuscript accepted on January 09, 2017

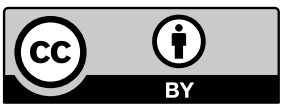

Motriz. The Journal of Physical Education. UNESP. Rio Claro, SP, Brazil - eISSN: 1980-6574 - under a license Creative Commons - Version 3.0 